\title{
A comparative study of nivolumab and axitinib in terms of overall survival, treatment continuation, and cost for patients with metastatic renal cell carcinoma
}

\author{
MICHIO KIMURA ${ }^{1}$, EISEKI USAMI ${ }^{1}$, HITOMI TERAMACHI ${ }^{2}$ and TOMOAKI YOSHIMURA ${ }^{1}$ \\ ${ }^{1}$ Department of Pharmacy, Ogaki Municipal Hospital, Ogaki, Gifu 503-8502; \\ ${ }^{2}$ Laboratory of Clinical Pharmacy, Gifu Pharmaceutical University, Gifu 501-1196, Japan
}

Received August 26, 2019; Accepted December 6, 2019

DOI: $10.3892 /$ mco. 2020.1978

\begin{abstract}
Nivolumab and axitinib has recommended as a second-line treatment in patients with metastatic renal cell carcinoma (mRCC) after tyrosine kinase inhibitor treatment. In this study, overall survival (OS), treatment continuation, and the cost of nivolumab and axitinib-the second-line treatment agents for $\mathrm{mRCC}$-were compared and examined. Herein, we retrospectively surveyed patients with pathologically confirmed mRCC, treated with nivolumab $(n=9)$ or axitinib $(n=16)$ at Ogaki Municipal Hospital (Ogaki, Japan) between January 2012 and May 2019. The treatment periods for the nivolumab-and axitinib-administered groups were 5.4 (range: 1.4-21.3) and 3.4 (range: 0.3-28.1) months, respectively $(\mathrm{P}=0.089)$. The postponement periods for the nivolumab- and axitinib-administered groups were 7 (range: 0-186) and 0 (range: 0-262) days, respectively, and the difference was statistically significant $(\mathrm{P}=0.008)$. The median OS for patients treated with nivolumab and axitinib was 12.3 (range: 1.5-25.5 months) and 9.2 (range: 2.2-55.0 months) months, respectively $(\mathrm{P}=0.633)$. The one-year cost estimates for axitinib and nivolumab in clinical practice were $\$ 60,694.2$ and $\$ 86,544.4$, respectively $(\mathrm{P}=0.017)$. We found that despite frequent interruptions in nivolumab administration and a longer postpaonement period for the nivolumab-administered group than for the axitinib-administered group, both groups exhibit comparable treatment duration and OS.
\end{abstract}

\section{Introduction}

The Check Mate 025 study recently showed that second-line treatment with nivolumab extends the overall survival (OS)

Correspondence to: Dr Michio Kimura, Department of Pharmacy, Ogaki Municipal Hospital, 4-86 Minaminokawa-cho, Ogaki, Gifu 503-8502, Japan

E-mail: kimkim0305nao@yahoo.co.jp

Key words: nivolumab, axitinib, advanced/recurrent renal cancer, second-line treatment, overall survival of patients with metastatic renal cell carcinoma (mRCC) and exhibits a higher objective response rate than everolimus (1). Moreover, as a second-line treatment, the National Comprehensive Cancer Network has recommended cabozantinib, nivolumab, axitinib, and lenvatinib plus everolimus as category 1 after tyrosine kinase inhibitor (TKI) treatment for patients (2). The European Society of Medical Oncology considers axitinib as an optional treatment (recommended degree II, B) after TKI treatment (3). In Japan, cabozantinib is not approved for use at present, and nivolumab and axitinib have become key drugs as the second-line treatment after TKI treatment. Nivolumab is a humanized antibody against programmed cell death-1 (PD-1). It inhibits the binding of PD-1 to its ligands PD-L1 and PD-L2 and suppresses tumor growth by inducing the proliferation of cancer antigen-specific $\mathrm{T}$ cells and enhancing cytotoxic activity (4). Meanwhile, axitinib is a potent, selective, second-generation inhibitor of vascular endothelial growth factor receptor (VEGFR)1, 2 and 3 that blocks VEGFR signalling at sub-nanomolar concentrations (5).

Axitinib is a TKI that is similar to sunitinib and pazopanib; thus, axitinib may not be effective after treatment failure with first-line agents because of the similarity between axitinib and first-line TKIs. In contrast, the mechanism of action of nivolumab differs from that of TKIs, so there is a possibility that it may be effective as second-line treatment for mRCC. To date, there has been no study comparing the OS, treatment continuation, and drug cost for nivolumab and axitinib as a second-line treatment in patients with mRCC after TKI treatment. The determination of these parameters will demonstrate the effectiveness, safety, and medical and economic superiority of the treatment regimen. Eventually, this can guide decision making for treatment selection. In the present study, OS, treatment continuation, and the cost of nivolumab and axitinib-the second-line treatment agents for mRCC-were compared and examined.

\section{Patients and methods}

Patient selection. The present study retrospectively surveyed 26 patients with pathologically confirmed mRCC, who were treated with nivolumab or axitinib at Ogaki Municipal Hospital (Ogaki, Japan) between January 2012 and May 2019. Patients who discontinued their treatment due to financial reasons $(1 / 26)$ 
were excluded. Patient characteristics, adverse events (AEs), treatment period, reasons for discontinuation or postponement, postponement period, OS, and drug cost over the treatment duration were analyzed retrospectively using the data collected from the electronic charts and pharmacy service records. OS was defined as the interval between the initiation of nivolumab or axitinib administration as the second-line treatment and the date of death from any cause. AEs were evaluated according to the Common Terminology Criteria for Adverse Events, version 4.0 (6), and the most severe grades during chemotherapy were reported. The drug cost for one year in clinical practice was calculated based on the amount of the drug actually used and the dosing period. Personal information was protected in the aggregated data. The Institutional Review Board of Ogaki Municipal Hospital, Ogaki, Japan, approved the present study under the approval no. 20190627-7.

Drug treatment. Before September 2016, axitinib was selected as the second-line treatment for mRCC because nivolumab was not covered by insurance. Axitinib was administered at a dose of $5 \mathrm{mg}$ twice a day for 2 consecutive weeks. If axitinib was tolerated, the dose was increased as necessary to $7 \mathrm{mg}$ once a day. If tolerability was observed after two consecutive weeks of administration, the dose of axitinib was increased as necessary to $10 \mathrm{mg}$ twice a day.

After September 2016, nivolumab was selected as the second-line treatment for $\mathrm{mRCC}$ because it was covered by insurance. From September 2014 to July 2018, nivolumab was administered at a dose of $3 \mathrm{mg} / \mathrm{kg}$ of body weight, through a $60 \mathrm{~min}$ intravenous infusion every 2 weeks. From August $2018,240 \mathrm{mg}$ of nivolumab was administered through a 60-min intravenous infusion every 2 weeks.

Dose modifications were permitted for axitinib but not for nivolumab.

Statistical analysis. The Mann-Whitney's U test or the $\chi^{2}$ test of independence (Fisher's exact probability test) was used to analyze patient characteristics, AEs, and reasons for discontinuation. The Kaplan-Meier log-rank test was used to compare OS. $\mathrm{P}<0.05$ was considered to indicate a statistically significant difference. All statistical analyses were performed using the EZR software (v1.30; Saitama Medical Center, Jichi Medical University), which is a graphical user interface for $\mathrm{R}$ (The R Foundation for Statistical Computing) (7).

\section{Results}

Patient characteristics. The patient characteristics are summarized in Table I. The median ages of patients receiving nivolumab and axitinib were 68 (range: 58-84) and 71 (range: 51-74) years, respectively. Patients were categorized into the following risk groups (favourable/ intermediate/poor) according to the International $\mathrm{mRCC}$ Database Consortium (IMDC): 1/6/2 for nivolumab-administered patients and $1 / 12 / 3$ for axitinib-administered patients $(\mathrm{P}=0.667,0.876,0.834)$.

Treatment duration and reasons for discontinuation during second-line treatment. Treatment duration and reasons for discontinuation of second-line treatment are summarized in Table II. The treatment enforcement periods for the nivolumab- and axitinib-administered groups were 5.4 (range: 1.4-21.3) and 3.4 (range: 0.3-28.1) months, respectively, and the difference between the two groups was not statistically significant $(\mathrm{P}=0.089)$. The number of nivolumab-administered patients who discontinued treatment due to progressive disease (PD), AEs, deterioration of condition, and deterioration in performance status (PS) was 6,0,1 and 0, respectively. Conversely, the number of axitinib-administered patients who discontinued treatment due to PD, AEs, deterioration of condition, and deterioration in PS was 6, 6, 1 and 2, respectively. Discontinuation of treatment in axitinib-administered patients owing to AEs included the following observations: Nausea, vomiting, diarrhea, and cerebral hemorrhage.

Postponement period and reasons for postponement during second-line treatment. The postponement period and reasons for postponement are summarized in Table III. The postponement period for the nivolumab- and axitinib-administered groups were 7 (range: 0-186) and 0 (range: 0-262) days, respectively, and the difference between the two groups was statistically significant $(\mathrm{P}=0.008)$. The main reasons for postponement for the nivolumab-administered group were holidays, increase in blood sugar levels, disease condition deterioration (ascites and pain control), and poor medical history (hospitalization for acute myocardial infarction, acute cardiac insufficieny and angina pectoris), among other reasons.

Adverse events analysis. The major AEs for the nivolumaband axitinib-administered groups are summarized in Table IV. The AEs for the nivolumab-administered group consisted of increased creatinine levels $(44.4 \%)$, anemia (33.3\%), pruritus $(33.3 \%)$, rash $(33.3 \%)$, and increased creatine kinase levels $(33.3 \%)$. The AEs for the axitinib-administered group consisted of anorexia (41.2\%), hoarseness (35.5\%), diarrhea (29.4\%), hand-foot syndrome $(23.5 \%)$, and nausea $(23.5 \%)$. AEs of grade 3 or higher in the nivolumab-administered group were AST/ALT increase (1) and creatinine (1), while those in the axitinib-administered group were nausea (1) and diarrhea (1).

Overall survival. Fig. 1 shows the Kaplan-Meier survival curves for the OS of patients administered with nivolumab or axitinib as second-line treatment. The median OS for nivolumab- $(\mathrm{n}=9)$ and axitinib-administered patients $(\mathrm{n}=16)$ was 12.3 (range: 1.5-25.5) and 9.2 (range: 2.2-55.0) months, respectively (log-rank test, $\mathrm{P}=0.633$ ).

Drug cost. The administration of axitinib and nivolumab to patients at the dose indicated in the package insert resulted in a 2 week cost of $\$ 2,333.9$ and $\$ 3,918.4$, respectively. The one-year cost estimates for axitinib and nivolumab in clinical practice were $\$ 60,694.2$ and $\$ 86,544.4$, respectively $(\mathrm{P}=0.017)$ (Table V).

\section{Discussion}

In this study, we examined the characteristics of nivolumab and axitinib in terms of overall survival, treatment continuation, and cost for patients with mRCC. Our results indicated that despite frequent interruptions in nivolumab administration and a longer 
Table I. Patient characteristics.

\begin{tabular}{|c|c|c|c|}
\hline Characteristic & Nivolumab, $n=9$ & Axitinib, $n=16$ & P-value \\
\hline \multicolumn{4}{|l|}{ Age, years } \\
\hline Median (range) & $68(58-84)$ & $71(51-74)$ & $0.869^{\mathrm{a}}$ \\
\hline \multicolumn{4}{|l|}{ Sex, n } \\
\hline Male & 8 & 13 & $0.617^{\mathrm{b}}$ \\
\hline Female & 1 & 3 & \\
\hline Metastatic site, $\mathrm{n}$ & & & $0.264^{\mathrm{b}}$ \\
\hline Lung & 3 & 10 & \\
\hline Liver & 3 & 4 & \\
\hline Bone & 2 & 3 & \\
\hline Lymph node & 6 & 6 & \\
\hline Peritoneal & 3 & 0 & \\
\hline Recurrence & 2 & 2 & \\
\hline Left adrenal gland & 2 & 0 & \\
\hline Pleura & 1 & 1 & \\
\hline \multicolumn{4}{|l|}{ Organization group, $\mathrm{n}$} \\
\hline Clear cell & 8 & 15 & 0.187 \\
\hline Papillary & 1 & 0 & \\
\hline IMDC risk group, $\mathrm{n}$ & & & $0.878^{\mathrm{b}}$ \\
\hline Favorable & 1 & 1 & \\
\hline Intermediate & 6 & 12 & \\
\hline Poor & 2 & 3 & \\
\hline \multicolumn{4}{|l|}{ Body surface area, $\mathrm{m}^{2}$} \\
\hline Median (range) & $1.64(1.42-1.78)$ & $1.62(1.41-2.01)$ & $0.655^{\mathrm{a}}$ \\
\hline \multicolumn{4}{|l|}{$\mathrm{CrCl}, \mathrm{mg} / \mathrm{ml}$} \\
\hline Median (range) & $41.2(7.9-69.2)$ & $55.6(30.0-123.3)$ & $0.165^{\mathrm{a}}$ \\
\hline First-line treatment drugs & & & $0.586^{\mathrm{b}}$ \\
\hline Sunitinib & 6 & 9 & \\
\hline Pazopanib & 3 & 4 & \\
\hline Sorafenib & 0 & 2 & \\
\hline Temsirolimus & 0 & 1 & \\
\hline Drugs used after third-line treatment & & & $0.426^{\mathrm{b}}$ \\
\hline None & 2 & 6 & \\
\hline Temsirolimus & 1 & 5 & \\
\hline Sunitinib & 1 & 2 & \\
\hline Axitinib & 4 & 3 & \\
\hline Pazopanib & 0 & 5 & \\
\hline Everolimus & 0 & 3 & \\
\hline Sorafenib & 0 & 1 & \\
\hline Nivolumab & 0 & 2 & \\
\hline $\begin{array}{l}\text { Treatment ongoing at data collection } \\
\text { (Nivolumab or axitinib) }\end{array}$ & 2 & 1 & $0.524^{\mathrm{b}}$ \\
\hline
\end{tabular}

${ }^{a}$ Mann-Whitney U test. ${ }^{b} \chi^{2}$ test for independence test. IMDC, International mRCC Database Consortium; $\mathrm{CrCl}$, creatinine clearance.

postponement period for the nivolumab-administered group than for the axitinib-administered group, both groups exhibit comparable treatment period and OS. Moreover, the cost for nivolumab administration was higher than that for axitinib administration.

In the Check Mate 025 study comparing the nivolumab- and everolimus-administered groups, nivolumab did not extend PFS, but it did extend OS. A previous study has suggested that the so-called durable response may produce long effect duration (1). Another study has revealed that the effect lasts for approximately one year after the end of treatment (8). The Japanese subgroup analysis from the Check Mate 025 study showed that the OS of both nivolumab- and axitinib-administered groups is higher 
Table II. Second-line treatment period and reasons for discontinuation.

\begin{tabular}{lcc}
\hline Period and reason & Nivolumab, $\mathrm{n}=9$ & Axitinib, $\mathrm{n}=16$ \\
\hline $\begin{array}{l}\text { Second-line treatment period, months } \\
\text { Median (range) }\end{array}$ & $5.4\left(1.4-21.3^{\mathrm{c}}\right)$ & $3.4\left(0.3-28.1^{\mathrm{c}}\right)$ \\
Number of regimens used after second-line treatment, $\mathrm{n}$ & $1(0-2)$ & $1(0-4)$ \\
Median (range) & $6.089^{\mathrm{a}}$ \\
Reasons for discontinuation & 0 & 6 \\
Progressive disease & 1 & 6 \\
Adverse events & 0 & 1 \\
Deterioration of condition & 2 & 2 \\
Deterioration in performance status & & 1 \\
Treatment ongoing at data collection & & $0.140^{\mathrm{b}}$
\end{tabular}

${ }^{\mathrm{a}}$ Mann-Whitney $\mathrm{U}$ test; ${ }^{\mathrm{b}} \chi^{2}$ test for independence test; ${ }^{\mathrm{c}}$ not reached.

Table III. Postponement period and reasons for postponement during second-line treatment.

\begin{tabular}{lccc}
\hline Period and reason & $\begin{array}{c}\text { Nivolumab } \\
(\mathrm{n}=9)\end{array}$ & $\begin{array}{c}\text { Axitinib } \\
(\mathrm{n}=16)\end{array}$ & P-value \\
\hline $\begin{array}{l}\text { Postponement period, days } \\
\text { Median (range) }\end{array}$ & $7(0-186)$ & $0(0-262)$ & $0.008^{\mathrm{a}}$ \\
Rate of postponement, $\%$ & 16.40 & 13.50 & $0.008^{\mathrm{b}}$ \\
Reasons for postponement, $\mathrm{n}$ & & & $0.025^{\mathrm{b}}$ \\
Holiday & 7 & 0 & \\
Adverse events & $1^{\mathrm{c}}$ & 0 & \\
Deterioration of condition & $1^{\mathrm{d}}$ & $1^{\mathrm{g}}$ & \\
Palliative surgery & 0 & 2 & \\
Poor medical history & $2^{\mathrm{e}}$ & 0 & \\
Patient's convenience & 2 & 0 & \\
Other reasons & $2^{\mathrm{f}}$ & 0 & \\
\hline
\end{tabular}

${ }^{a}$ Mann-Whitney U test; ${ }^{b} \chi^{2}$ test for independence test; ${ }^{c}$ Increased blood sugar level; dascites, pain control; 'hospitalized for acute myocardial infarction, acute cardiac insufficieny and angina

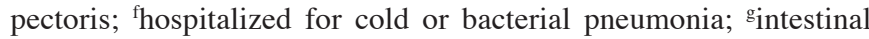
obstruction. Rate of postponement $=$ [postponement period (days) $\mathrm{x} 100 \mathrm{~J} / \mathrm{second}-\mathrm{line}$ treatment period (days).

than that of the global population (9). Similarly, in this study, no significant difference in the OS between nivolumab- and axitinib-administered patients was observed. This observation may explain the reason for the difference in the treatment regimens between the Western countries and Japan. The ESMO Guideline considers axitinib as an optional treatment agent. However, the NCCN Guideline regards it as the standard drug for second-line treatment $(3,10)$. In Japan, axitinib, nivolumab and sorafenib are recommended for both second- and third-line treatments. In the event of a shortage of TKI and mammalian target of rapamycin (mTOR) inhibitors, there is a possibility that there is no difference in the priority between nivolumab and axitinib as second-line treatment drugs. In this study, various TKI and mTOR inhibitors, such as unitinib, pazopanib, and everolimus,
Table IV. Treatment-related adverse events reported in $10 \%$ or more of treated patients in either group.

\begin{tabular}{|c|c|c|}
\hline & Nivolumab, n=9 & Axitinib, $n=16$ \\
\hline Event & $\begin{array}{c}\text { Any grade } \\
\text { number of } \\
\text { patients }(\%)\end{array}$ & $\begin{array}{c}\text { Any grade } \\
\text { number of } \\
\text { patients }(\%)\end{array}$ \\
\hline Leucopenia & $1(11.1)$ & $0(0.0)$ \\
\hline Neutropenia & $1(11.1)$ & $1(6.3)$ \\
\hline Anemia & $3(33.3)$ & $2(12.5)$ \\
\hline Increased AST/ALT level & $2(22.2)$ & $1(5.9)$ \\
\hline Increased creatinine level & $4(44.4)$ & $0(0.0)$ \\
\hline Fatigue & $2(22.2)$ & $0(0.0)$ \\
\hline Anorexia & $0(0.0)$ & $7(43.8)$ \\
\hline Nausea & $0(0.0)$ & $4(25.0)$ \\
\hline Stomatitis & $0(0.0)$ & $3(18.8)$ \\
\hline Diarrhea & $2(22.2)$ & $5(31.3)$ \\
\hline Constipation & $1(11.1)$ & $1(6.3)$ \\
\hline Pruritus & $3(33.3)$ & $1(6.3)$ \\
\hline Rash & $3(33.3)$ & $2(12.5)$ \\
\hline Hyperkalemia & $1(11.1)$ & $1(6.3)$ \\
\hline Increased CPK level & $3(33.3)$ & $0(0.0)$ \\
\hline Hypothyroidism & $1(11.1)$ & $3(18.8)$ \\
\hline HFS & $0(0.0)$ & $4(25.0)$ \\
\hline Epistaxis & $0(0.0)$ & $2(12.5)$ \\
\hline Hypertension & $0(0.0)$ & $8(37.5)$ \\
\hline Hoarseness & $0(0.0)$ & $6(12.5)$ \\
\hline Proteinuria & $0(0.0)$ & $2(11.8)$ \\
\hline Hyperglycemia & $1(11.1)$ & $0(0.0)$ \\
\hline
\end{tabular}

AST, aspartate aminotransferase; ALT, alanine aminotransferase; CPK, creatine kinase; HFS, hand-foot syndrome.

were used as third-line treatments. The administration of nivolumab to patients with $\mathrm{mRCC}$ was postponed due to poor medical history or holidays. However, treatment duration and 
Table V. Annual drug cost.

\begin{tabular}{lccccr}
\hline Regimens & $\begin{array}{c}\text { Standard dose } \\
\text { (calculated at 50 kg) }\end{array}$ & $\begin{array}{c}\text { Single dose } \\
\text { drug cost }\end{array}$ & $\begin{array}{c}\text { One-year cost } \\
\text { estimate }\end{array}$ & $\begin{array}{c}\text { One-year cost } \\
\text { estimate in clinical practice }\end{array}$ & P-value \\
\hline Axitinib & $10 \mathrm{mg}$ & $\$ 166.7$ & $\$ 60,846.3$ & $\$ 60,694.2$ & $0.017^{\mathrm{a}}$ \\
Nivolumab & $240 \mathrm{mg}$ & $\$ 3,918.4$ & $\$ 101,877.2$ & $\$ 86,544.4$ & \\
\hline
\end{tabular}

${ }^{a}$ Mann-Whitney U test.

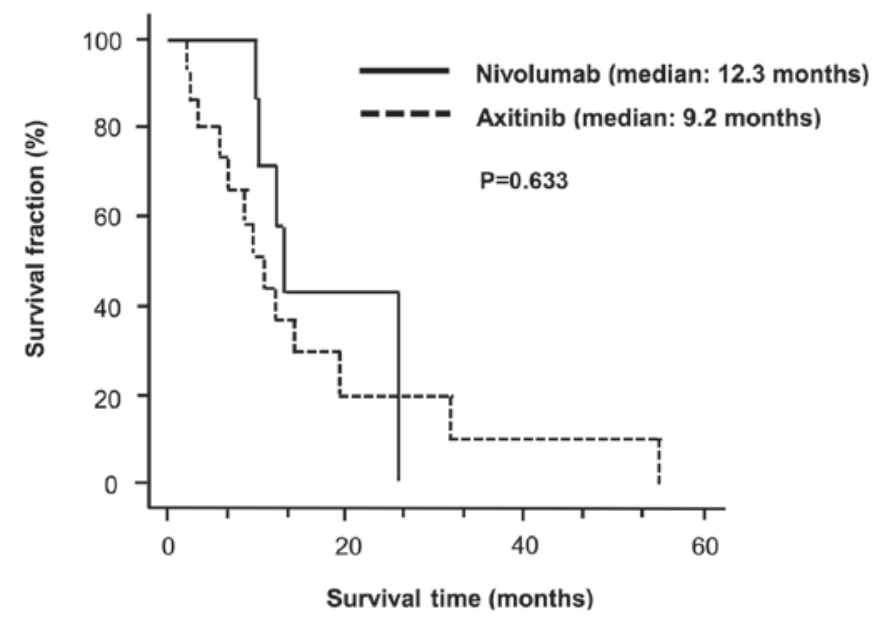

Figure 1. Kaplan-Meier survival curves show overall survival following second-line therapy with nivolumab and axitinib. No significant difference in survival was observed between the two groups.

OS were identical despite the longer postponement period than that for the axitinib-administered group. The so-called durable response might have produced this effect. The sustained response of patients with $\mathrm{mRCC}$ treated with nivolumab has also been observed in phase I and phase II trials $(8,11)$. In the case of molecularly targeted drugs such as axitinib, postponement of treatment may lead to a risk of disease progression.

Immune checkpoint inhibitors exert their clinical effects by enhancing the antitumor effects of $\mathrm{T}$ cell, including restoration of tumor immunity and development of autoimmune diseases. Therefore, the expression level and pattern of the AEs is largely different from those of the conventional molecular targeted drugs. In this study, results suggested that AE profiles differ between nivolumab and axitinib. The AE status of the nivolumab-administered group in our study is similar to that of the Check Mate 025 study and the study by De Giorgi et al $(1,12)$. The absence of subjective symptoms, such as nausea, maintains the quality of life (QOL) of the nivolumab-administered patients. Immune-related AEs that should be particularly noted include thyroid dysfunction and type I diabetes, both of which are also described in this study (8). The administration of axitinib to patients with mRCC was often stopped due to symptoms such as nausea, vomiting, and diarrhea. These patients may have exhibited similar AEs if they used TKIs similar to axitinib as first-line treatment drugs.

In the UK, the cost-effectiveness assessment of expensive drugs is conducted by the National Institute for Health and Clinical Excellence (NICE). NICE did not recommend using market-authorized nivolumab within the Cancer Drugs Fund to treat locally advanced, unresectable, or metastatic urothelial carcinoma in adults who had previously received platinum-containing therapy (13). The cost-effectiveness of nivolumab for patients with recurrent/metastatic head and neck squamous cell carcinoma and advanced non-flat non-small-cell lung cancer is lower $(14,15)$. In this study, the one-year estimate of the cost of nivolumab was significantly higher than that of axitinib in clinical practice $(92,559,26$ vs. $64,912,49$ yen, respectively). However, the dose of axitinib can be increased to $20 \mathrm{mg} /$ day for patients that present a low blood level elevation, which can increase the annual drug cost. The cost-effectiveness of using nivolumab and axitinib in clinical practice is not available; however, both drugs are expected to be less cost-effective (13-15).

The results of this study will aid in the selection of the appropriate second-line treatment drug after TKI treatment. To guide decision making for the choice of second-line treatment drug after TKI treatment, we suggest that nivolumab takes precedence over axitinib for the treatment of mRCC patients with a medical history, poor general condition, or severe AEs. Considering that nivolumab is more expensive than axitinib, determining the effects at an early stage and performing early transition of drug treatment may reduce the overall drug cost.

For future studies, it will be necessary to accumulate a considerable number of clinical cases to accurately determine drug administration period. The number of patients was limited in this study because it was reported as an initial experience in a single-center clinical practice setting. In the future, it is hoped that a positive randomized controlled trial will be implemented.

These findings provide novel insights into the characteristics of nivolumab and axitinib for the treatment of patients with $\mathrm{mRCC}$, and can guide decision making for the choice of second-line treatment drug after TKI treatment.

\section{Acknowledgements}

Not applicable.

\section{Funding}

No funding was received.

\section{Availability of data and materials}

The datasets used and/or analyzed during the current study are available from the corresponding author on reasonable request. 


\section{Authors' contributions}

MK, EU, HT and TY conceived and designed this study. MK acquired the data. MK, EU, HT and TY drafted the manuscript. All authors read and approved the final manuscript.

\section{Ethics approval and consent to participate}

The present study was approved by the Institutional Review Board of Ogaki Municipal Hospital (approval no. 20190627-7). The requirement of informed consent was waived by the Institutional Review Board.

\section{Patient consent for publication}

Not applicable.

\section{Competing interests}

The authors declare that they have no competing interests.

\section{References}

1. Motzer RJ, Escudier B, McDermott DF, George S, Hammers HJ, Srinivas S, Tykodi SS, Sosman JA, Procopio G, Plimack ER, et al Nivolumab versus everolimus in advanced renal-cell carcinoma. N Engl J Med 373: 1803-1813, 2015.

2. Motzer RJ, Jonasch E, Agarwal N, Bhayani S, Bro WP, Chang SS, Choueiri TK, Costello BA, Derweesh IH, Fishman M, et al: Kidney cancer, version 2.2017, NCCN clinical practice guidelines in oncology. J Natl Compr Canc Netw 15: 804-834, 2017.

3. Escudier B, Porta C, Schmidinger M, Riou-Leclercq N, Bex A, Khoo V, Gruenvald V, Horwich A and ESMO Guidelines Committee: Renal cell carcinoma: ESMO Clinical Practice Guidelines for diagnosis, treatment and follow-up._Ann Oncol 27: v58-v68, 2016

4. Wang C, Thudium KB, Han M, Wang XT, Huang H, Feingersh D, Garcia C, Wu Y, Kuhne M, Srinivasan M, et al: In vitro characterization of the anti-PD-1 antibody nivolumab, BMS-936558, and in vivo toxicology in non-human primates. Cancer Immunol Res 2: 846-856, 2014.
5. Sonpavde G, Hutson TE and Rini BI: Axitinib for renal cell carcinoma. Expert Opin Investig Drugs 17: 741-748, 2008.

6. US Department Of Health And Human Services: Common terminology criteria for adverse events (CTCAE) version 4.0. United States, National Cancer Institute, Sept 15, 2009. http://www. acrin.org/Portals/0/Administration/Regulatory/ CTCAE_4.02_2009-09-15_QuickReference_5X7.pdf.

7. Kanda Y: Investigation of the freely available easy-to-use software 'EZR' for medical statistics. Bone Marrow Transplant 48: 452-458, 2013.

8. Motzer RJ, Rini BI, McDermott DF, Redman BG, Kuzel TM, Harrison MR, Vaishampayan UN, Drabkin HA, George S, Logan TF, et al: Nivolumab for metastatic renal cell carcinoma: Results of a randomized phase II trial. J Clin Oncol_33: 1430-1407, 2015.

9. Tomita Y, Fukasawa S, Shinohara N, Kitamura H, Oya M, Eto M, Tanabe K, Kimura G, Yonese J, Yao M, et al: Nivolumab versus everolimus in advanced renal cell carcinoma: Japanese subgroup analysis from the checkmate 025 study. Jpn J Clin Oncol 47: 639-646, 2017.

10. National Comprehensive Cancer Network: Clinical practice guidelines in oncology: Kidney Cancer. version 2. JNCCN · June 2017.

11. McDermott DF, Drake CG, Sznol M, Choueiri TK, Powderly JD, Smith DC, Brahmer JR, Carvajal RD, Hammers HJ, Puzanov I, et al: Survival, durable response, and long-term safety in patients with previously treated advanced renal cell carcinoma receiving nivolumab. J Clin Oncol 33: 2013-2020, 2015.

12. De Giorgi U, Cartenì G, Giannarelli D, Basso U, Galli L, Cortesi E, Caserta C,Pignata S, Sabbatini R, Bearz A, et al: Safety and efficacy of nivolumab for metastatic renal cell carcinoma: Real-World results from an expanded access programme. BJU Int 123: 98-105, 2019.

13. Grimm SE, Armstrong N, Ramaekers BLT, Pouwels X, Lang S, Petersohn S, Riemsma R, Worthy G, Stirk L, Ross J, et al: Nivolumab for treating metastatic or unresectable urothelial cancer: An evidence review group perspective of a NICE single technology appraisal. Pharmacoeconomics 37: 655-667, 2019.

14. Zargar M, McFarlane T, Chan KKW and Wong WWL: Cost-Effectiveness of nivolumab in recurrent metastatic head and neck squamous cell carcinoma. Oncologist 23: 225-233, 2018.

15. Matter-Walstra K, Schwenkglenks M, Aebi S, Dedes K, Diebold J, Pietrini M, Klingbiel D, von Moos R and Gautschi O; Swiss Group for Clinical Cancer Research: A cost-effectiveness analysis of nivolumab versus docetaxel for advanced nonsquamous NSCLC including PD-L1 testing. J Thorac Oncol 11: 1846-1855, 2016. 